\title{
Development of Electronic Learning Tools to Improve the Quality of Elementary Linear Algebra Course
}

\author{
Hendra Syarifuddin \\ Mathematics Department of Universitas Negeri Padang \\ Padang, Indonesia \\ hendrasy@yahoo.com
}

\author{
I Made Arnawa \\ Mathematics Department of Andalas University \\ Padang, Indonesia
}

\begin{abstract}
The focus of the research is to develop a constructivist electronic teaching aids for Elementary Linear Algebra. The teaching aid is useful for learning using ACE cycle that consists of three components: activities, classroom discussion, and exercises. Developmental research design is choose for developing electronic teaching aids and for implementing the teaching aid, the experimental research design is selected. The research is conducted in two years focussing on producing valid, practical, and effective electronic teaching aids. The research activities are divided into two phases. Phase one aim at producing a valid prototype of teaching aids. For this purpose, need assessment, curriculum analysis, review of related literature, and designing the prototype of the teaching aids where done. The designed prototype was validated by two qualified Elementary Linear Algebra reviewers. The finding showed that the designed prototype fulfilled the criteria of content and construct validity. Phase two of the research was conducted at Mathematics Department of Universitas Negeri Padang. The aim of the second phase is to see the effectiveness of the designed prototype.
\end{abstract}

Keywords-APOS theory, ACE cycle, constructivist

\section{INTRODUCTION}

Studying mathematics at the college level generally involves high-level cognitive skills, such as analytical skills, synthesis, and evaluation, rather than simply remembering factual knowledge or simple applications of various formulas or principles. As a result, many students are experiencing difficulty in studying the standard topics contained in highschool curricula, such as Linear Equation System, the Vector Space, the Inner Product Space, and others [1].

The APOS theory developed by Dubinsky et al [2] is a learning approach devoted to mathematics learning at the college level, integrating computer use, learning in small groups, and taking into account the mental constructs of students in understanding a mathematical concept. These mental constructs are: action, process, object and schema which is abbreviated as APOS. APOS theory basically embraces constructivism, especially constructivism developed by Vygotsky, that is social constructivism. According to Dubinsky et al [2], knowledge and understanding of mathematics owned by students is the result of construction and interaction of the student with others in dealing with mathematical problems. To accommodate learning based on APOS theory it is necessary to have an electronically designed learning device, enabling students to learn actively.

This study aims to produce electronic learning devicesoriented constructivism for lecture Algebra Linear Elementary. The planned learning devices are electronic modules with constructivist characteristics. Furthermore, the learning approach to be used is the learning approach with APOS theory, where this approach has a constructivist philosophy. Based on the research product that will be produced, the specific purpose of this research is to produce constructivist, constructive, practical, and effective constructivist learning device.

According to Asma [3] Development of learning tools is a set of learning programs based on the system approach. Approach of learning system is a series of events that affect students to occur the learning process. These events can be done by students either individually or in groups by utilizing existing learning resources in accordance with the learning objectives to be achieved. The results of this system approach are expected to solve the learning problems effectively and efficiently.

In relation to the above, the model used in the development of this mathematical learning tool is Model Degeng [4] which consists of eight steps as follows; 1) analysis of objectives and characteristics of the field of study, 2) analysis of learning resources (constraints), 3) analysis of student characteristics, 4) establish learning objectives and instructional content, 5) set goals and instructional content, 5) Establish a material organizing strategy, Establishing a Learning Material Delivery Strategy, 7) Establishing Learning Management Strategy, 8) Development of Learning Outcome Measurement Procedure.

Constructivist scholars agree that learning mathematics involves the active manipulation of meaning, not just numbers and formulas. Each stage of the learning of mathematics should be oriented to an investigation or search process. Therefore, lecturers need to provide a learning environment where students can achieve basic concepts, algorithmic skills, heuristic processes, and collaborative habits [5].

Referring to the constructivist lecturers' features and the essence of constructivist mathematics learning, it is necessary to select learning models that enable students to practice developing understanding, reasoning, communication, and problem-solving skills. The learning model based on constructivist theory among others is learning with APOS theory approach. 
The learning cycles in APOS theory include: (i) computerassisted learning activities, (ii) classroom discussions, and (iii) exercises. Through computer learning activities, students can reduce abstract concepts to be more concrete, ie by exploring examples or not examples related to the concept or with the properties of the concept [6]. According to Leron \& Dubinsky [7] activities in the laboratory are intended to give students intuition about mathematical concepts. Similarly, Lakatos (1976) argued that a learning approach involving experiments can provide students with an intuition in understanding a theorem. Classroom discussion activities give students the opportunity to pose ways or strategies that may be more efficient than those found by other students, arguing in class discussions will be an invaluable exercise in an effort to improve students' ability to reason deductively, eventually improving students' ability in making mathematical proofs [8]. So, class discussions can foster creativity in students.

Training activities, intended to provide opportunities for students to apply concepts that have been mastered by students in solving some problems in mathematics. With this activity the students will gain a lot of experience about how the vagaries of the application of concepts in solving a problem. Thus, learning with APOS theory provides an opportunity for students to be creative, gain intuition, and gain experience in math. This means, the APOS theory "is quite promising" if used as an approach in learning Linear Elementary Algebra.

Lugo and Herman [9] argue that teachers can design efficient and effective learning by utilizing computer technology. Computers as a medium in learning can be used to respond to three main things, namely; the low attention and motivation of the students, the decreasing of students' memory, and the difficulty of the students connecting knowledge from one discipline to another.

According to Ayers [1], in understanding a mathematical concept, students do mental constructions. These mental constructions can be helped through computer-based activities. In constructing its knowledge, lecturers can assist students through a learning approach designed to stimulate the occurrence of expected mental constructions. According to Dubinsky \& Tall [10], this can be done through: (i) provision of learning devices with computers (electronic modules) so that students can elaborate and reflect on computer activities; (ii) make computer programs in appropriate programming languages, so that this programming activity goes hand in hand with the student's effort to create a mental construction process.

Computers can also make mathematical concepts more meaningful for students, because through computer activity (exploring examples and not examples related to concepts under study) students can see abstract mathematical concepts from the concrete side, so that students can helped understand the abstract concepts. When an abstract idea is raised on a computer, it becomes concrete in the mind of the student. All this can be done through the provision of programming tasks so that mental constructions are made "powerful" in improving knowledge and understanding of mathematics. Moreover, through computer programming students can do reflection (how computers do that) and what processes are involved [10].

So in this study, at the stage Activities lecturers designing learning for students to learn by using computers. On each computer is provided electronic module. This module contains material descriptions, examples of implementation, and practice questions. They studied the contents of the modules and solved the problems in groups, one group consisting of 3 or 4 students.

According to Putra [11] basically cooperative learning model was developed to achieve at least three learning objectives namely learning outcomes, acceptance of diversity, and the development of social skills. Putra argued that cooperative learning model has several advantages in developing the potential of students, including: the relationship of mutual benefit among group members, the development of cooperation spirit, and the spirit of healthy competition among group members and between groups. Therefore, the application of this model can effectively develop student potential.

\section{METHOD}

The research design that was used is developmental research. This design is considered very appropriate for research activities that aim to produce a product that is valid, practical, and effective. In relation to the resulting product in the form of learning devices, the research activities are divided into two stages, namely; (i) prototype stage to produce a valid learning device, and (ii) implementation stage, aiming to see the effectiveness of the resulting learning device.

The focus of research in phase I is the creation of prototypes of constructivist-oriented electronic learning devices that are valid in terms of content and construct. The validation process is done by two Linear Elementary Algebra learning experts. Content validity refers to the suitability of the material in the device with the curriculum, while the validity of the order refers to the suitability of the device arrangement with the expected criteria; constructivist learning approach.

\section{RESULT}

Electronic learning devices (electronic modules) to improve the quality of Linear Elementary Algebra courses are prepared based on needs analysis, curriculum analysis, and literature review. This device is designed using Microsoft Frontpage software, with this software every unit in the learning device can connect easily.

The contents of electronic modules designed and developed refer to the learning approach based on APOS theory, ie learning with ACE cycle (Activity, Classroom Discussion, and Exercice). The material division is designed for each lecture week. For research purposes, the designed course materials are materials for seven lecture weeks (material until mid-semester). In one lecture week there are three learning activity nodes; lab activities, class discussions, and exercises. In the lab activities contained learning objectives and learning materials in the 
week that students can learn independently. In the class discussion section contain materials to be discussed in groups. And, in the exercise there are questions to be done by students at home.

The electronic module prototype for the Linear Elementary Algebra lecture that has been prepared as described above has been validated to two experts in the Linear Elementary Algebra field. The validation process is done by discussing with experts. The discussion focused on the things contained in table 1 . The validation results from the experts, in general there is no significant change that needs to be done on prototype electronic module for lecture Algebra Linear Elementary. Based on this condition can be said that the prototype that has been designed to meet the criteria of validity. Furthermore, to see the effectiveness and effectiveness of the developed device, the researcher use it in learning activity of Algebra Linear Elementary at Study Program of Mathematics Education at State University of Padang. Learning using this tool is carried out for half a semester ( 8 weeks of lecture including midterms exam).

From the observations during the learning activities took place can be concluded that students can follow the learning well by using learning tools developed. By using t-test $(\alpha=$ $0,05)$, it can be concluded that learning acyl Aljabar Linear Elementer students who follow the learning by using this learning tool is also better when compared with student learning outcomes that follow the conventional learning.

\section{CONCLUTION}

The first phase of the study has resulted a valid electronic learning device for elementary linear algebra courses. The validation results show that the designed prototype meets the criteria of content validity and construct validity. From the use of learning tools in the classroom can be concluded that the device has met the aspects of practicality and effective to improve student learning outcomes.

\section{REFERENCES}

[1] Ayers, T. et al. (1988). "Computer Experiences in Learning Composition of Functions". Journal for Research in Mathematics Education. 19 (3), 246259.

[2] Dubinsky, E. \& McDonal, M. (2001). "APOS: A Construktivist Theory of Learning in Undergraduate Mathematics Education Research". Dalam D. Holton (ed.). The Teaching and Learning of Mathematics at University Level. Dordrecht: Kluwer Academic Publishers.

[3] Asma, Nur. (2000). Pengembangan Paket Pembelajaran. Malang: Universitas Malang.

[4] Degeng, IN. S. (1994). Strategi Pembelajaran.: Kajian Teori dan aplikasi. Jurnal Sumber Belajar, Januari. 1 (1), (17-31).

[5] Cobb, P. Yackel, E. \&Wood, T. 1992. A constructivist alternative to the representational views of mind in mathematics education. Journal For Research in Mathematics Education, 23(1),2-33.

[6] Asiala, M. et al. (1997). "A Framework for Research and Curriculum Development in Undergraduate Mathematics Education". Dalam E. Dubinsky et al. (ed.). Reading in: Cooperative Learning for undergraduate Mathematics. Washington DC: The Mathematical Association of America.
[7] Leron, U. \& Dubinsky, E. (1995). "An Abstract Algebra Story". American Mathematical monthly, 102 (3), 227-242.

[8] Alibert, D. \& Thomas, M. (1991). "Research on Mathematical proof". Dalam D. Tall (ed.). Advanched Mathematical Thingking. Dordrecht: Kluwer Academic Publishers.

[9] Lugo, Gabriel G \& Russel L. Herman. (2002). Fostering Multimedia Instruction in Mathematics. Wilmington: UNCW.

[10] Dubinsky,E. \& Tall, D. (1991). "Advanched Mathematical Thinking and Computer”. Dalam D. Tall (ed.). Advanched Mathematics Thinking. Dordrecht: Kluwer Academic Publishers.

[11] Putra, Amali. (2003). Penerapan Model Pembelajaran "Student Team Achievement Devisions” Dalam Pembelajaran Fisika. Padang: Universitas Negeri Padang 